\title{
Examining the Effects of Hypothetical Modifications in Permitting Procedures and River Conditions on Whitewater Boating Behavior
}

\author{
Christos Siderelis and Roger L. Moore \\ North Carolina State University
}

In this study we combine a travel cost modeling approach with the surveyed stated preferences of whitewater boaters at the Chattooga River to examine the possible effects of six hypothetical modifications in river use permitting process or changes in river conditions on intended future trip behavior of respondents. To varying degrees, all of the hypothetical modifications in river use permitting (procedures and pricing) and changes in river conditions would lead selfguided (kayaking) visitors to significantly reduce the number of river trips they planned to take in the future, while four of the six resulted in significant reductions for guided (rafting) visitors. Results suggest that the travel cost modeling approach, supplemented with users' trip responses to hypothetical scenarios, can be an appropriate way to predict the effects of possible management alternatives. While the estimation method requires a somewhat complicated cross-sectional statistical process, the software is readily available and the information provided can be quite helpful for policy makers and managers. Our consumer surplus estimates are consistent with previous boating studies at $\$ 745$ per guided rafting trip per party $(\$ 149$ per person) and $\$ 444$ per self-guided kayaking trip per party ( $\$ 113$ per person)

KEYWORDS: Whitewater boating, travel cost model, outdoor recreation, stated preferences, intended behavior.

Managers of public rivers face a variety of complex challenges in at tempting to provide high quality outdoor recreation opportunities while simultaneously protecting the natural resources upon which these opportunities depend (Wild and Scenic Rivers Act, Public Law 90-542 (as amended). October 2, 1968). Issues related to crowding, user conflicts, concessionaire oversight, boater permitting, user safety, parking, human waste, water quality, resource monitoring, neighboring landowner relations, state and federal regulations, and many more, can make recreational rivers one of the most challenging of all recreational settings to manage. Popular whitewater rivers are typically the most complex and challenging of all. While past research and decades of experience in attempting to address these challenges can provide

Address corresponding to: Christos Siderelis, Professor, Department of Parks, Recreation and Tourism Management, Box 8004, College of Natural Resources, North Carolina State University Raleigh, NC 27695-8004. Phone: (919) 513-1700; Fax: (919) 515-3687; Email: Chris_ Siderelis@ncsu.edu.

Author note: The authors are both professors in the Department of Parks, Recreation and Tourism Management, College of Natural Resources, at North Carolina State University. They would like to thank the National Park Service and the nonprofit American Rivers, Inc. for supporting the research on which this paper is based. 
valuable guidance for managers, it would be extremely helpful to have more objective ways of predicting the effects of possible management alternatives in advance. This would enable managers to assess which approaches would be most effective in accomplishing management objectives and most palatable for river users themselves. This research was undertaken to attempt to do this along a very popular whitewater river in the southeastern U.S. - the Wild and Scenic segment of the Chattooga.

USDA Forest Service officials and significant stakeholders groups interested in the well-being of the 57-mile Wild and Scenic segment of Chattooga River face ongoing and particularly difficult challenges regarding river policies and conditions. How, for example, would introducing different river permitting schemes affect current users' behaviors and experiences? Or, which of several site development schemes would be the most beneficial in efforts to reduce river congestion? Or, how would natural changes in river conditions affect the behaviors and experiences of river users? We attempt to address these and related questions by presenting a series of hypothetical scenarios to Chattooga River users then modeling the effects these different scenarios would have on their intended future river behavior.

The Chattooga River is well known and quite popular among whitewater boating enthusiasts. Many people recognize this 57-mile river segment, which was added to the National Wild and Scenic River System in 1974, because of its use as a location in the film Deliverance. It is located in northwestern SC, northeastern GA and southwestern $\mathrm{NC}$ with the headwaters and the beginning of its wild and scenic segment near the base of Whiteside Mountain in NC. From there, it flows south for about 10 miles to where it becomes the border between northwestern SC and northeastern GA for the remainder of its designated wild and scenic length. When the 57-miles of the Chattooga were designated as Wild and Scenic by Congress, it was the first river in the southeast to be added to the National Wild and Scenic River System. The vast majority of the segment is located within and surrounded by the Sumter, Chattahoochee, and Natahala National Forests. Most of the river corridor is primitive and characterized by dense forests with undeveloped shorelines and it is very popular for both whitewater kayaking as well as guided whitewater rafting. The whitewater rafting benefits to visitors, in particular, have been examined by previous research and found to be substantial. Using the travel cost method, Bowker, English, and Donovan (1996) computed the consumer surplus for a guided rafting trip on the Chattooga River to be from $\$ 146$ to $\$ 351$ in 2002 dollars (i.e., $\$ 119$ to $\$ 286$ in 1994). ${ }^{1}$ Consumer surplus is an economic welfare measure and as such is referred to as a benefit

\footnotetext{
${ }^{1}$ The consumer surplus reflected the different wage rates $(0 \%, 25 \%$, and $50 \%)$ the authors invoked when computing the opportunity costs of travel times. Consumer surplus is calculated by integrating the area under the demand curve between user's current travel cost to and from a site and the travel cost that would eliminate site use. Due to the nonlinearity of the countdata demand function, a point estimate of consumer surplus is used. The consumer surplus corresponding to the semi-logarithmic recreation demand specification of a count-data regression is calculated as follows: $\left(-1 / \mathrm{b}_{\mathrm{TC}}\right)$, where $\mathrm{b}_{\mathrm{TC}}$ is the parameter estimate on the travel cost.
} 
in the recreation economics literature. The reason for the range in consumer surplus was that the authors uniformly lowered both the reported trip costs as well as the imputed trip costs in estimating household demand for guided rafting.

\section{Use of Hypothetical Scenarios in Previous Research}

Any modifications in the policies regarding river use permits or even potential changes in natural resources conditions have the potential to affect how often visitors will visit a river. The purpose of this study was to examine the effects of hypothetical modifications in Chattooga River permitting and changes in river conditions on users' intentions to take whitewater boating trips there in the future. An advantage of having respondents state their preferences for hypothetical modifications lies in the analyst's ability to predict how respondents will change their future trips in response to various use permitting schemes and changes in river conditions that currently do not exist, enabling policy makers and managers to assess the possible impacts of changes they are or might consider. An analysis of those intended future trips, even though they are hypothetical, is particularly valuable when anchored to the actual whitewater boating trips taken by respondents in the past, as was done in this research.

According to past research, three key requirements must be met in evaluating users' stated preferences for future trips in response to hypothetical variations such as the distribution of use permits or possible changes in river conditions (Bockstael \& McConnell, 1991):

1. Some way of linking observable user behaviors to administrative policy variants.

2. An experimental approach that ensures the intended change in recreation behavior is relevant to the hypothetical variants in administrative policies. "Hypothetical" in this context means that the survey respondents are not expected to pay fees, nor is remuneration provided based on the alterations in fee payment schedules or site conditions to suit the outcomes of the experiments (Hudson, 2003).

3. The ability to evaluate the impacts of the policy variants on the users' intended future behaviors.

In meeting these requirements, Englin and Cameron (1996) employed a panel data methodology. Their statistical estimation method deals explicitly with survey data that contain a dependent variable having multiple intended trip responses per person and where the number of trips is a nonnegative integer with zero trips possible. They use the panel data estimator to study the mean differences in alternative trip cost scenarios among a cross-section of Nevada anglers. ${ }^{2}$ Readers should be aware that the use of intended trip

\footnotetext{
${ }^{2}$ See Wooldridge (2000, pp. 441-446) or other statistical texts (Cameron \& Trivedi, 1998, pp. 275-300) for a comprehensive discussion of random and fixed effects and the Hausman specification test.
} 
responses to hypothetical questions is different from the more common contingent valuation method where the analyst proposes different contingent dollar amounts (including a "protest" response of zero dollars) to each hypothetical situation to estimate the effects of trip cost variations on the current quantity of trips demanded. Similar methodological approaches to the one followed in this research were applied by Siderelis, Moore, and Lee (2000) in collecting data to elicit users' intended number of trips to hypothetical changes in lake conditions, and Chase, Lee, Schulze, and Anderson (1988) in collecting data to elicit information on foreign tourists' hypothetical park visitation behaviors at alternative entrance fee levels.

Overall, the examination of intended trips has been found to be a viable approach in estimating the impacts of the policy variants on the users' intended visitation to a site. Loomis (1993), for example, successfully used a test-retest analysis of trip responses when investigating the reliability of intended visitation and changes in the water-levels of three lakes. More recently, Grijalva, Berrens, Bohara, and Shaw (2002) tested the validity of intended survey data before a proposed management change having to do with restricting access to rock climbing areas in Texas and, then, with surveys after implementing restrictions. The authors concluded that intended trips is a valuable supplement to actual preference data when administrative policy proposals are outside the range of historical conditions. Their findings suggest that respondents are better able to react to hypothetical questions that require them to measure changes in their intended trips when considering their past travel behaviors. Their findings are also important in providing evidence that users do act on their intentions to increase or decrease their visitation under different hypothetical circumstances, particularly if the users are familiar with the site.

This research builds on the above studies and contributes to an understanding of the role that experimental economics can play in the management of recreation resources. Specifically, we illustrate the use of an intended trip response model to generate experimental data from a series of hypothetical survey questions to determine how different river permitting procedures and conditions would affect respondents' future trips to the wild and scenic segment of the Chattooga River. Augmenting the travel cost model with experimental data in this way can provide valuable guidance for resource managers as they consider future actions. This controlled experimental design can provide managers with an objective way of predicting the effects of possible changes in current operations in advance; thereby, allowing them to assess which hypothetical changes in existing operating policies and procedures that might be most effective in accomplishing agency objectives and yet be palatable for recreation users themselves.

\section{Methods}

In implementing the intended trip response method, we form the panel data consisting of eight trip responses by first asking respondents, "About how many trips did you take to the Chattooga River during the past twelve 
months? Please consider only the 57-mile wild and scenic segment of the Chattooga River during the past 12 months." The respondent is next asked the hypothetical question, "About how many trips do you expect to take to the Wild \& Scenic segment of the Chattooga River during the next twelve months? Please consider only the 57-mile Wild and Scenic segment of the Chattooga River during the next 12 months." Their intentions include the option of intending to take zero trips. Of the six remaining trip response scenarios, the first four questions address hypothetical variations in the river permitting process (Table 1). Although none of the policy variants listed in Table 1 was being explicitly considered by the river's managers at the time of this study, they are plausible alternatives available to them. The hypothetical scenarios examined were designed to provide valuable information to Forest Service officials in terms of how acceptable various river permit schemes might be among visitors, and how feasible it might be to generate increased revenues through permit fees to help deal with maintenance backlogs and control river congestion, even though the primary purpose of permit compliance and fees are generally to improve the quality of visitor services (Bengston \& Fan, 2002, pp. 7-9). At the time of this research, all self-guided boaters (i.e., kayakers) were required to obtain a no-cost, selfregistration, river permit, and many self-guided boaters paid a $\$ 3$ parking fee, depending on which river access area they used. The next question concentrates on the potential user crowding at access areas and on the river. The design of the question determines how respondents might alter their behaviors if more crowded conditions existed. It was believed that this information could help guide Forest Service officials in best setting the total level of boating allowed and in allocating an equitable balance between guided and self-guided river use. The final question examined the impact of a hypothetical change in the Chattooga River water level on respondents' intended future trips (Kakoyannies \& Stankey, 2002, pp. 35-36). The Chattooga's daily water flow averaged 323 cubic feet per second in 2002 with an historical daily mean water flow of $450(\mathrm{~N}=63$ years) (Retrieved July 2003 from http://waterdata.usgs. gov/sc/nwis/discharge?). The mean gauge height was approximately 1.7 feet in 2002 with water levels varying at the gauge from 1.2 to 3.5 feet. Only very experienced boaters run the river when levels are over 2.0 feet and levels above 3.0 feet are considered dangerous.

\section{Estimating Future Recreation Trips}

We consider a user's satisfaction with whitewater boating conditions to be a function of their number of trips per season to the Chattooga River, the river's quality, and each user's annual income. Annual income is viewed as the household budget constraint on the user's whitewater boating behavior. The user will maximize satisfaction subject to the trip's overall cost to gain river access in light of the remaining budgeted expenditures for household goods and services. We augment the recreation demand function for whitewater boating by combining the actual trips taken by a respondent during the past 12-months and the respondent's future trips intended for the next 12-months as: 


\section{TABLE 1 \\ Six Hypothetical Changes in River Use Permitting and River Conditions (As Asked in the Study Questionnaire)}

The next six questions are based on current river management policies, but are purely hypothetical. We ask you to think about each scenario, then, answer the question about how the hypothetical change might affect your river use in the next twelve months.

(D1-PERMIT ALTERNATIVE 1) The current Forest Plan sets daily limits for both self-guided and commercially guided boating on the Wild \& Scenic segment of the Chattooga River. Suppose you were required to obtain a free permit that had to be reserved in advance and was available at convenient locations, to float the river. If you and the others in your group were required to obtain a free river use permit in advance, how many trips would you take to the Wild \& Scenic Chattooga River during the next twelve months? Please assume that river quality stays at its current level.

(D2-PERMIT ALTERNATIVE 2) Suppose you were required to obtain a free permit available only to walk-ins on a first-come, first serve basis, to float the Chattooga River. Assume walkin permits are available the day before or the day of the river trip and are available at convenient locations. If you and the others in your group were required to obtain walk-in permits, how many trips would you take to the Wild \& Scenic Chattooga River during the next twelve months? Please assume that river quality stays at its current level.

(D3-PERMIT ALTERNATIVE 3) Suppose there was non-refundable permit fee of $\$ 5$ per person for a day-use permit to float the Chattooga River for both commercially guided and self-guided boaters. Day-use fees would be used to cover the cost of the permit system, existing river programs, and providing better information to river users. If such a fee system was put in place, how many trips would you take to the Wild \& Scenic Chattooga River during the next twelve months? Please assume that river quality stays at its current level.

(D4-INCREASED USE EFFECT) The Forest Service estimates that 32,000 people took commercially guided boating trips and 23,000 people took self-guided trips on the Wild \& Scenic Chattooga River in the year 2000. Suppose that during the next twelve months and beyond, you expected to see twice as many boaters on the Chattooga than you saw during your last trip there. How many trips would you take to the Wild \& Scenic Chattooga River during the next twelve months?

(D5-PERMIT ALTERNATIVE 4) Under the more congested boating conditions described in question \#7, suppose there was non-refundable permit fee of $\$ 10$ per person for a day-use permit to float the Chattooga River for both commercially guided and self-guided trips. How many trips would you take to the Wild \& Scenic Chattooga River during the next twelve months?

(D6-WATER LEVEL EFFECT) A minimum water level of 1.1 feet at the Highway 76 water gauge is considered necessary for boating on the Wild \& Scenic Chattooga River. Actual water levels range from below one foot to approximately 3 feet. Suppose the river level was impaired by man-made or natural conditions that left the river level below one foot for the next 12 months. How many trips would you take to the Wild \& Scenic Chattooga River during the next twelve months?

Note. The openended response format for each of the six questions was, " Trips in next 12 months." 


$$
\begin{aligned}
\text { TRIPSij }= & b_{0}+b_{\mathrm{TC}}\left(\text { TRIP_COST }_{\mathrm{j}}\right)+b_{1 \mathrm{NC}}\left(\mathrm{INCOME}_{\mathrm{j}}\right)+b_{\mathrm{D} 1}\left(\mathrm{D}_{\mathrm{ij}}\right) \\
& +b_{\mathrm{D} 2}\left(\mathrm{D}_{\mathrm{ij}}\right)+b_{\mathrm{D} 3}\left(\mathrm{D} 3_{\mathrm{ij}}\right)+b_{\mathrm{D} 4}\left(\mathrm{D} 4_{\mathrm{ij}}\right)+b_{\mathrm{DD}}\left(\mathrm{D}_{\mathrm{ij}}\right)+b_{\mathrm{D} 6}\left(\mathrm{D} 6_{\mathrm{ij}}\right) \\
& +b_{\mathrm{PT}}\left(\mathrm{P}_{-} \text {TRIPS }_{\mathrm{ij}}\right)+b_{\mathrm{A}}\left(\text { ACTIVITY }_{\mathrm{ij}}\right)+\mathrm{e}_{\mathrm{ij}} \cdot
\end{aligned}
$$

The dependent variable TRIPS per year is for the $i^{\text {th }}$ trip response per $j^{\text {th }}$ respondent to each of the six hypothetical questions in Table 1, as well as the number of past trips and the number of future trips intended with no changes in river conditions and use permitting. On the right-hand side of Equation 1, are the shift coefficients $b_{\mathrm{D} 1} \ldots b_{\mathrm{D} 6}$ where each coefficient is the slope of the dummy variable corresponding to a particular hypothetical question. ${ }^{3}$ We evaluate the hypothetical questions (D1 . . D6, as specified in Equation 1) against the base category response that is the future trips that would be taken with no hypothetical changes in use permitting or river conditions. The base category is therefore not specified in the trip response model. The respondent's number of trips during the past 12-months (as reported in the study questionnaire) is identified by an indicator variable, $\mathrm{P}$ _TRIPS. The primary boating activities are guided whitewater rafting where the services are purchased from an outfitter and self-guided kayaking. We include the trip costs for theoretical reasons even though respondent's trip cost did not change with the trip response to each hypothetical question. Because users of different annual incomes will not make the same trip expenditure choices, neither the trip cost nor annual income enters Equation 1 alone (Mendelsohn, Matzkin, Peterson, \& Rosenthal, 1994). Using the reported total trip expenditures per party to include the mileage travel cost as the trip cost variable, avoids the common assumption of typical travel cost models that the trips of different lengths have the same trip cost (Kerkvliet \& Nowell, 1999, Parson \& Wilson, 1997). ${ }^{4}$ Previous research indicates that

\footnotetext{
${ }^{3}$ There is a subtle but important issue related to expected values (King, Tomz, \& Wittenberg, 2000). The intended trips, when estimated with a Poisson regression, are different from predicted trips. Predicted trips contain both fundamental and estimation uncertainty. Intended trips are averaged over the variability arising from sheer randomness, leaving only the estimation uncertainty caused by not having an infinite number of observations (King, Tomz, \& Wittenberg). However, the predicted and intended trips are the same in linear models, but can differ in nonlinear cases. The values are often close, if nonlinearity is not severe.
}

${ }^{4}$ Trip price was computed by the following equation:

$$
P=[(d * 0.14)+(w * h * 0.33)] * 2+f .
$$

$d=$ Reported one-way distance from visitor's origin to Chattooga River in miles multiplied by $\$ 0.14$ per mile for fuel and upkeep as reported by the American Automobile Association and Runzheimer International for V6 automobiles adjusted from $\$ 1.20$ a gallon gas in 1996 to $\$ 1.64$ a gallon in 2002 (Autoweek, April 1, 1996, p. 9).

$w=$ Household hourly wage rate as measured by annual household income divided by reported hours worked per week. If missing, household annual income was divided by 2080 work hours in a year and 0.33 was the fraction of the imputed wage rate to value time.

$h=$ Reported hours spent traveling to Chattooga River. If missing, one-way distance was divided by an average of $54 \mathrm{mph}$, which was computed from reported data on miles traveled and time in travel (Hellerstein, Woo, McCollum \& Donnelly, 1993).

$f=$ Average cost per trip as estimated by respondents (e.g., permit fees, access fees for parking, and guide fees paid, motels, restaurants, etc.). If missing, average reported permit and access expenses per person for guided trips $(X=\$ 73.73$ per person) and self-guided $(X=$ $\$ 6.20$ per person) were imputed by multiplying the reported number of persons in the travel party by estimated average expenses. 
individuals are able to accurately report trip expenditures like access fees in ex-post mail surveys (Champ \& Bishop, 1996).

Of specific research interest in this study are the questions relating to the hypothetical modifications in river use permitting and changes in river conditions and how they influence respondents' future trip-taking behaviors to the Chattooga. By focusing on those coefficients beside the specified variables (D1, ..., D6) in Equation 1 having to do with the hypothetical questions of interest, we state the following null hypotheses and the corresponding alternative hypotheses for each of the six coefficients:

$$
\begin{aligned}
& \mathrm{H}_{\mathrm{O}}: \mathrm{b}_{\mathrm{D} 1}=0 ; \mathrm{H}_{\mathrm{O}}: \mathrm{b}_{\mathrm{D} 2}=0 ; \mathrm{H}_{\mathrm{O}}: \mathrm{b}_{\mathrm{D} 3}=0 ; \mathrm{H}_{\mathrm{O}}: \mathrm{b}_{\mathrm{D} 4}=0 ; \mathrm{H}_{\mathrm{O}}: \mathrm{b}_{\mathrm{D} 5}=0 ; \\
& \mathrm{H}_{\mathrm{O}}: \mathrm{b}_{\mathrm{D} 6}=0 ; \\
& \mathrm{H}_{\mathrm{A}}: \mathrm{b}_{\mathrm{D} 1} \neq 0 ; \mathrm{H}_{\mathrm{A}}: \mathrm{b}_{\mathrm{D} 2} \neq 0 ; \mathrm{H}_{\mathrm{A}}: \mathrm{b}_{\mathrm{D} 3} \neq 0 ; \mathrm{H}_{\mathrm{A}}: \mathrm{b}_{\mathrm{D} 4} \neq 0 ; \mathrm{H}_{\mathrm{A}}: \mathrm{b}_{\mathrm{D} 5} \neq 0 ; \\
& \mathrm{H}_{\mathrm{A}}: \mathrm{b}_{\mathrm{D} 6} \neq 0 .
\end{aligned}
$$

\section{Data Collection}

Because of the multitude of river access points along the 57 miles of the Wild and Scenic segment of the Chattooga River, we implemented a subsample approach to obtain a representative sample of users from the various river sections. In 2002, we obtained mailing lists of customers from two of the three commercial outfitters. Copies of on-site use permits (which are required for the non-commercially boaters prior to their departures) were obtained from the USDA Forest Service as well. Consistent with the Forest Service terminology, we labeled these two boating segments as "guided" (typically whitewater rafting) and "self-guided" (typically kayaking and canoeing), respectively. The sample sizes were roughly proportional to each segment's share of overall river use, based on 2001 Forest Service usage rates of the Chattooga River (USDA Forest Service, 2002). The guided sample was proportional to each outfitter's market share and was drawn using a systematic sampling scheme. The self-guided sample of river users was systematic and drawn from the on-site permit records kept at the Sumter Forest office (USFS). To avoid over-sampling avid users, permits containing the same user's name were discarded and only the most recent permit retained. In this manner, the more frequent as well as the less frequent visitors were included in the sample selection process. The 180 annual pass holders for fee-based parking were also included as a part of the self-guided sample. After three separate mailings to the full sample, at approximately two-week intervals, we obtained a response rate of $43 \%$ (i.e., 841 returned/1,936 mailed). Of the 841 questionnaires, 692 contained the complete data necessary for trip response analysis. Table 2 presents a summary of the characteristics of guided and self-guided boater and their trips.

Whether pre-planned or impulsive, the respondents' choices of guided and self-guided river trips and the respondents' motives for participating in their river activities may in fact influence respondents' outlook about future visits and their stated trip responses (i.e., number of intended future trips) 
TABLE 2

Descriptive Statistics

\begin{tabular}{lcc}
\hline & Self-guided (SD) & Guided (SD) \\
\hline Trip Characteristics & & \\
Trips taken during the past 12-months & $12.0(19.9)$ & $1.2(0.7)$ \\
Intended trips for next 12-months & $14.2(22.5)$ & $0.9(1.0)$ \\
Trip costs per party & $\$ 185.53(\$ 88.98)$ & $\$ 713.28(\$ 411.24)$ \\
Group size & $3.9(2.9)$ & $5.0(4.6)$ \\
Miles traveled (one-way) & $158(235)$ & $305(295)$ \\
Percent on overnight stay & $42 \%$ & $75 \%$ \\
Length of stay on-site (hours) & $6.26(4.56)$ & $6.56(2.62)$ \\
Respondents Characteristics & $38.7(9.7)$ & $42.7(9.7)$ \\
Age & $43.3(12.8)$ & $45.46(11.31)$ \\
Hours worked per week & $\$ 55,658(\$ 36,228)$ & $\$ 79,037(\$ 43,405)$ \\
Annual income & Combined responses equaled $11 \%$. \\
Gone to another river if Chattooga unavailable? & & \\
\hline
\end{tabular}

to hypothetical variants in the river permitting process. We suspected that the guided and the self-guided boaters were two distinct user segments that should be modeled separately. In fact, the two-sample t-tests for the differences in the trip costs $(t=-13.5693)$ and annual incomes $(t=-6.6739)$ across these two boating segments were different at the 0.05 statistically significant level. There were also nine statistically significant differences between these two groups in terms of 22 possible motives for visiting the Chattooga River (Moore \& Driver, 2005). Those respondents who took guided boating trips were most strongly motivated by desires to take risks, to do something with his or her family, to learn about the countryside, and to test his or her endurance; while self-guided boaters wanted to be on his or her own, to use equipment, to think about personal values, to get exercise, and to share skill with others (Table 3 ).

Consequently, the trip response modeling was applied separately to each of the two whitewater boating segments to estimate the coefficients for the independent variables. The coefficients allowed for measures of the sensitivity of intended trips to the possible permit process modifications and changes in river conditions. Each trips response was a non-negative integer and the response could be for zero intended trips. Because of this, the trip response models took a Poisson count-data specification, which follow a semilogarithmic function form. ${ }^{5}$ Of possible concern was the Poisson distribution that assumes the conditional mean and conditional variance that would be equal for the dependent variable. A violation of this assumption would result

\footnotetext{
${ }^{5}$ Hellerstein (1991) describes the statistical analysis and treatment for non-normal data attributes of trip counts per season (year) as the dependent variable in a count-data estimator.
} 
TABLE 3

Recreation Experience Preferences for Visiting the Chattooga River by Guided and Self-Guided Visitors $(n=583)$

\begin{tabular}{lrrr}
\hline \multicolumn{1}{c}{ Preferences $^{\mathrm{a}}$} & Coefficient & Std Err & z-value \\
\hline To be on my own & -0.4227 & 0.1381 & -3.06 \\
To take risks & 0.9083 & 0.1525 & 5.95 \\
To use my equipment & -1.2459 & 0.1503 & -8.28 \\
To do something with my family & 0.5977 & 0.1068 & 5.59 \\
To learn about the countryside & 0.4883 & 0.1484 & 3.29 \\
To think about my personal values & -0.6514 & 0.1519 & -4.29 \\
To get exercise & -0.5491 & 0.1851 & -2.97 \\
To share my skills and knowledge with others & -0.4739 & 0.1427 & -3.32 \\
To test my endurance & 0.4616 & 0.1552 & 2.97 \\
Summary Statistics (see note): & & & \\
Observed versus predicted, correctly classified & $89.07 \%$ & & \\
Log likelihood & -157.45 & & \\
LR $\chi^{2}(22)$ & 493.21 & & \\
Efron's $\mathrm{R}^{2}$ & 0.68 & & \\
McKelvey \& Zavoina's ${ }^{2}$ & 0.80 & & \\
\hline
\end{tabular}

Note. Results are from a maximum-likelihood logit estimation to fit the dichotomous dependent variable for guided rafting $(=1)$ and self-guided boating $(=0)$. The Efron's $\mathrm{R}^{2}$ and the McKelvey and Zavoina's $\mathbf{R}^{2}$ are goodness of fit measures for binary outcomes (Long \& Freese, 2001).

"The response format for each decision variable ranged from "not at all important" (1) to "extremely important" (5).

an overdispersion in trip counts-a distributional misspecification that would underestimate the standard errors.

\section{Results and Discussion}

Guided respondents took a mean of 1.2 trips during the past 12 months with a standard deviation of \pm 0.7 trips and met the distributional assumption of a Poisson distribution. Alternatively, our sample of self-guided boaters took a mean of 12.0 trips per year with a standard deviation of \pm 19.9 trips. The size of the standard deviation, almost twice the mean number of trips, indicated an overdispersion in trips. Application of the negative binomial regression to account for this overdispersion and the resulting Wald test on the estimated dispersion coefficient, an additional term in the negative binomial regression, led us to reject the hypothesis of no dispersion in trips (Stata Corporation, Version 8, Cross-sectional time-series, 2003, p. 148).

Englin and Cameron (1996) choose a fixed-effect specification of a travel cost model in analyzing their panel data as opposed to a random effect specification. Other analysts, like Whitehead, Haab, and Huang (2000) or Chase et al. (1998), apply the random-effects estimator to fit the panel data. 
The random effects approach assumes that the random error associated with the individual visitor effects are uncorrelated with other independent variables, something, according to Kennedy (1996) that is not likely to be the case. A Hausman specification test checked for whether the random effects model was the applicable approach for analyzing the respondents' contingent behaviors (Stata Corporation, Version 8, Volume 2, 2003, pp. 51-58). We first fitted the trip response model to the guided panel data (rafting) with a fixed-effects Poisson regression to capture the constant, individuallevel, behavioral effects of the six hypothetical questions. We next fitted a random-effects estimator to the same panel data as the fully efficient specification of a guided rafting respondent's behavior. The two estimates were then compared with the Hausman specification test under the null hypothesis of no correlation between the random error and the independent variables. The random-effects Poisson model was rejected $\left[\chi^{2}(7)=67.68, \operatorname{Pr}>\right.$ $\chi=0]$. Using the same Hausman test procedure, we fitted the randomeffects and fixed-effects negative binomial models to the self-guided (kayaking) panel data. Again, under the null hypothesis of no correlation between the random error and the independent variables, the random-effects negative binomial model was rejected $\left[\chi^{2}(9)=24.21, \operatorname{Pr}>\chi=0\right]$.

Both panel-data sets were unbalanced in their designs, meaning that we were not restricted in our estimations to respondents having to provide a complete set of trip responses to all the hypothetical questions (Stata Corporation, Version 8, Cross-Sectional Volume, 2003, pp. 160-172). Respondents, in fact, may have provided answers to two or more of the six questions, either ignoring the remaining questions entirely or leaving them unanswered. Table 4 displays the fixed-effects statistical results for the guided trip and self-guided trip responses to the hypothetical questions. The trip cost and annual income were constant within each respondent's answers to the hypothetical questions and these two variables were therefore omitted during the fixed-effects estimation process. The Wald chi-square values that measured whether the fixed-effects estimators adequately modeled respondents' trip responses to the hypothetical questions were statistically significant for guided rafting $\left[\chi^{2}(7)=239 ; \operatorname{Pr}>\chi^{2}=0\right]$ and self-guided $\left[\chi^{2}(9)=905\right.$; $\left.\operatorname{Pr}>\chi^{2}=0\right]$.

Our expectations were that the past and intended trip responses would be the same for both boating segments. In other words, there would be no significant unexplainable intentions in respondents' past and intended future trips. However, the guided rafting estimate for past trips (P_TRIPS) did differ significantly from the intended future trips (Table 4, Guided Rafting). Since the coefficient sign on the number of trips taken during the past 12months (P_TRIPS) was positive, guided rafting respondents had taken more trips in the past 12-months then they intended to in the next 12-months. As for the self-guided respondents, the number of trips during the preceding 12-months did not differ significantly from the intended trips to be taken during the next 12-months (Table 4, Self-guided). We assumed then that selfguided users would not change their past participation under the same future conditions. 
TABLE 4

Fixed-Effects Panel Data Estimates of Trip Responses to Hypothetical Questions (D1, . . , D6) with the Number of Trips During the Next 12 Months Being the Base Outcome

\begin{tabular}{lcccr}
\hline \multicolumn{4}{c}{ Guided Rafting $(\mathrm{n}=1,824)$} \\
\hline & & Coefficient & Std Err & Z-value \\
\hline Trips during past 12 months & PTRIPS & 0.33548 & 0.00804 & 4.18 \\
Expected trips next 12 months if . & & & & \\
$\quad$ Free permit, reserve in advance & D1 & $0.00580^{*}$ & 0.09276 & 0.06 \\
Free permit, first-come, first serve & D2 & -0.61311 & 0.10578 & -5.35 \\
$\$ 5$ permit per person & D3 & $-0.05761^{*}$ & 0.09316 & -0.61 \\
Non-refundable permit, \$10 per person & D4 & -0.71319 & 0.07062 & -5.97 \\
Observe twice the number of boaters & D5 & -0.38291 & 0.10035 & -3.61 \\
Water level below one foot for the next year & D6 & -1.77394 & 0.17499 & -9.68 \\
Summary Statistics: Log likelihood $=-1156 ;$ Wald $\chi 2(7)=239.54$ & & \\
\hline
\end{tabular}

\begin{tabular}{|c|c|c|c|c|}
\hline \multicolumn{5}{|c|}{ Self-guided $(\mathbf{n}=2,396)$} \\
\hline & & Coefficient & Std Err & Z-value \\
\hline Trips during past 12 months & PTRIPS & $-0.09988^{*}$ & 0.04616 & -2.16 \\
\hline \multicolumn{5}{|l|}{ Expected trips next 12 months if . . } \\
\hline Free permit, reserve in advance & D1 & -0.60718 & 0.05537 & -10.97 \\
\hline Free permit, first-come, first serve & D2 & -0.58989 & 0.05536 & -10.65 \\
\hline$\$ 5$ permit per person & D3 & -0.77238 & 0.05826 & -13.26 \\
\hline Non-refundable permit, $\$ 10$ per person & D4 & -1.41090 & 0.07316 & -19.28 \\
\hline Observe twice the number of boaters & D5 & -0.29941 & 0.05046 & -5.93 \\
\hline Water level below one foot for the next year & D6 & -1.90283 & 0.08828 & -21.55 \\
\hline Constant & & 1.66529 & 0.06227 & 26.74 \\
\hline \multicolumn{5}{|c|}{ Summary Statistics: Log likelihood $=-4,427 ;$ Wald $\chi 2(7)=905.09$} \\
\hline
\end{tabular}

Notes. A conditional fixed effects negative binomial (overdispersion) model was fit to the selfguided data, whereas the guided rafting data were fit with a conditional fixed-effects Poisson model.

${ }^{*} n s$ at 0.01 level.

At the time of this research, all users were required to obtain a no-cost, self-registration, river permit, with many self-guided boaters paying a $\$ 3$ parking fee depending on the river access area chosen. In Table 4 , the regression coefficients reflect the effects on respondents' intended trips of the six hypothetical modifications in the use permitting process and changes in river conditions (D1 . . D6) ${ }^{6}$ Both boating segments viewed the hypothetical modifications away from current conditions unfavorably. They apparently viewed the hypothetical modifications as constraints on their current behav-

\footnotetext{
${ }^{6}$ The dummy variable trap is the mistake of including too many dummy variables, one for each intended behavior question, along with the intercept in an equation (Woolridge, 2000, 213).
} 
iors as implied by the negative signs of the regression coefficients (Table 4). Overall, all the hypotheticals in river use permitting and changes in the river's natural conditions would lead visitors to reduce their planned river trips in the future.

\section{Guided Rafting}

The regression coefficients for two modifications which would require a reservation in advance (D1) or a $\$ 5$ permit per person (D3) were not significantly different from zero thereby failing to be rejected at the 0.01 level. This means that these two modifications in river use permitting would account for no significant change in the number of intended future trips planned by guided rafting respondents (Table 4, Column 2). Whereas, the null hypotheses representing regression coefficients for the imposition of a first-come, first-served permit (D2) and the payment of a non-refundable $\$ 10$ use permit per person designated to help reduce increased crowding (D5) were significantly different from zero. Therefore, theses two null hypotheses were rejected at the 0.01 level, which means that guided respondents were intent on taking significantly fewer planned trips in the next 12-months if the D2 or D5 scenarios were implemented (Table 4). From the guided respondent perspective, outfitters currently make the permitting process transparent to customers by existing arrangements with the Forest Service. We speculate that part of the reason that guided respondents are uncomfortable with the scenarios represented by D2 and D5 they would require customers to become involved in obtaining permits themselves. Respondents simply would be unwilling to demand more rafting trips under those circumstances.

\section{Self-guided Boating}

The six null hypotheses representing the regression coefficients of the hypothetical changes in river use permitting and the river's natural conditions were significantly different from zero. The six null hypotheses were rejected at the 0.01 level. Self-guided boaters clearly viewed changes to existing river use permitting by any one of the four permitting scenarios as having a definite negative influence on their future demand for trips to the Chattooga River (Table 4). The non-refundable permit of $\$ 10$ per person (D4) would have the most dramatic negative effect on their demand for future trips under those circumstances.

\section{Comparisons of Stated Preference Results}

In order to fully understand the effects of the hypothetical scenarios on boating behavior, the intended future trips related to the six hypothetical questions must be compared to the baseline category responses to the question, "About how many trips do you expect to take to the Wild \& Scenic segment of the Chattooga River during the next twelve months? Please consider only the 57-mile wild and scenic segment of the Chattooga River during the next 12 months." Under the conditions of no changes in river use permitting and boating conditions, guided rafters are intent on taking about 
one trip during the next 12-months ( $M=-0.9$ trips; $S D= \pm 1$ trip); whereas self-guided respondents are intent on taking a mean of 12 future trips (SD $= \pm 19.9$ trips). Against this base category of the intended trip responses, the marginal intended trip effects for each of the hypothetical modifications by boating segments are displayed in Table 5 as percentages. By viewing the magnitudes of the marginal changes in the demand for boating as a divergence between the perceived quality of the current river experience and the anticipated quality of a future visit, we can infer the degree of respondents' dissatisfaction or satisfaction with the various hypothetical modifications in the use permitting process and, in a relative sense, between the two different boating segments. Also, included in Table 5 are the relative rankings of the dissatisfaction by respondents with the alternative modifications to river use permitting and in the hypothetical changes in the river's condition in the parentheses.

From Table 5, the hypothetical change in the amount of existing congestion on the river (i.e., D5 where respondents would observe twice the number of boaters than they would normally see) has less of an impact on the respondent's demand for future trips than would a hypothetical change in the water-level flow to below one foot next year (D6). The mean gauge height was approximately 1.7 feet in 2002 with water levels varying at the gauge from 1.1 to 3.5 feet. The Chattooga River levels normally fluctuate between a minimum of 1.1 feet and a maximum of 3.5 feet. Only very experienced boaters run the river when levels are over 2.0 feet. The extreme

\section{TABLE 5}

The Marginal Effects of Hypothetical Questions as the Percentage Decreases in the Annual Intended Trips by Guided and Self-Guided Boating Segments

\section{Guided Rafting Self-Guided Boating}

Percent change in the number of intended trips during the next 12-months if ...

Permitting effects

Free permit, reserve in advance

Free permit, first-come, first serve

Refundable $\$ 5$ permit per person

Non-refundable permit, $\$ 10$ per person

Increased crowding effect

Observe twice the number of boaters

Water-level effect

Water level below one foot next year

$\begin{array}{ccc}\text { D1 } & \text { ns } & -46 \%(3) \\ \text { D2 } & -46 \%(2) & -45 \%(2) \\ \text { D3 } & \text { ns } & -54 \%(4) \\ \text { D4 } & -51 \%(3) & -76 \%(5) \\ & & -26 \%(1) \\ \text { D5 } & -32 \%(1) & -85 \%(6) \\ & & \end{array}$

Notes. Rankings in parentheses are from 1 , the lowest amount of dissatisfaction, to 5, the highest amount. Percentage changes is equal to $100[\exp (B)-1]$ where $B$ is the coefficient values from Table 4. The expected number of trips during the next 12-months was the base outcome measure $(100 \%)$ against which the percentages should be compared. The mean intended trips for the next 12 months was 0.9 trips $(S D= \pm 1$ trip) for guided rafters and 12 trips $(S D= \pm 19.9$ trips) for self-guided boaters.

ns not a statistically significant scenario. 
change in the water level flow such as below 1 foot (D6) would make parts of the river undesirable for whitewater boating by leaving some portions of the river difficult to navigate. This would result in a dramatically reduced satisfaction $(-80 \%)$ for both guided and self-guided boating segments and a significant decrease in future demand for Chattooga River trips (Table 5).

The bottom line is that most respondents appear to be content with the current river use permitting procedures and the river's conditions in contrast to any of the hypothetical scenarios examined. Of the four hypothetical use permitting questions, the non-refundable, $\$ 10$ per person permit (D4) would have the greatest adverse impact on the demand for future river trips by both the guided rafting $(-51 \%)$ and the self-guided boaters $(-76 \%)$ surveyed; even though the respondents were informed that the $\$ 10$ use permit fee would reduce the congestion on the river. A free use permit, on a firstcome, first-served basis (D2) would adversely affect the number of intended future trips by the guided and self-guided groups alike $(-46 \%$ and $-45 \%$, respectively). The free use permit, reserved in advance (D1) and the refundable, $\$ 5$ per person permit (D3) would result in the self-guided respondents demanding approximately half as many river trips during the next 12 months, or $-46 \%$ and $-54 \%$, respectively.

Finally, we compare our estimates of consumer surplus to values obtained from previous boating studies. In doing so, it is important to remember that simple comparisons of consumer surplus from the available econometric models are unlikely to determine the most appropriate view of a person's decision process. There are also informational differences among statistical models and the implicit assumptions inherent in the statistical estimations (Smith \& Kaoru, 1986). In applying an individual travel cost model to their data, Bowker et al. (1996) divide the travel costs by the number of household participants to estimate the consumer surplus in 2002 dollars of $\$ 146$ - $\$ 351$ (i.e., $\$ 119$ to $\$ 286$ in 1994 ) per guided rafting trip. The range in consumer surplus is attributable to the authors uniformly lowering reported and imputed individual trip costs in the specification of the travel cost model. Our estimated consumer surplus is $\$ 745$ per guided rafting trip, and for comparison with the Bowker et al. estimates on an individualized basis, our consumer surplus per trip is $\$ 149$ when divided by the mean party size $[=-(1 / .001342) / 5$ persons per-party $] .^{7}$ Alternatively for self-guided

\footnotetext{
${ }^{7}$ The trip cost coefficients for the purposes of calculating consumer surplus were obtained from two travel cost models for the number of trips taken during the past 12-months. The dependent variable was the number of rafting trips taken, a non-negative integer requiring count-data regression methods. A truncated Poisson regression estimated the trip cost coefficient for the guided rafting trips and a truncated negative binomial regression estimated the trip cost coefficient for the self-guided trips. The regressions were truncated to correct for zero truncation (i.e., all the trip observations contained at least one trip and no zero trips) as follows:

Variable

Poisson

Negative Binomial

Trip Cost

Annual Income $(\$ 10,000)$

Constant

Alpha (overdispersion parameter)

Sample size

$-0.001342(0.0003696)$

$0.017887(0.0281847)$

$-0.353821(0.2898674)$

287

$-0.0022506(0.0003571)$

$-0.0698507(0.0272340)$

$2.7184130(0.1960433)$

$1.0543240(0.2345226)$ 297
}

Notes. Coefficients and standard errors are in parentheses. 
river use (i.e., kayaking), the consumer surplus is $\$ 444$ per trip $(=-1 /$ -0.0022506 ) or $\$ 113$ per trip per individual. In a similar 2000 study of the Wild and Scenic West Branch of the Farmington River in Connecticut, the point estimates of consumer surplus using trip costs per party for self-guided river use was $\$ 230$ per trip and for floating the river with an inner tube requiring the services of an outfitter was $\$ 368$ per trip (Moore \& Siderelis, 2001).

The results of this study indicate that an experimental approach, such as the intended trip response model used here, can be effectively employed to elicit the marginal changes in future demand due to hypothetical policy variations. In this controlled experimental design, results were consistent with the actual recreation choices made by respondents and with the revealed preferences that self-guided respondents actually exhibit (Adamowicz, Swait, Boxall, Louviere, \& Williams, 1997). As such, we suggest that trip response modeling can be a valuable tool for evaluating the effects of current policies and potential variations in policies or site conditions in a wide range of outdoor recreation setting. Such an approach could help managers to evaluate alternative policies and management responses in advance in order to assess which would be most effective in accomplishing management objectives and which would be most palatable for users themselves.

\section{References}

Adamowicz, W., Swait, J., Boxall, P., Louviere, J., \& Williams, M. (1997). Perceptions versus objective measures of environmental quality in combined revealed and stated preference models of environmental valuation. Joumal of Environmental Economics and Management, 32, 65-84.

Autoweek (1996). Breaking down driving costs by mile and by year. Autoweek (April 1), 9 .

Bengston, D. N., \& Fan, D. P. (2002). The recreational fee demonstration program on the national forests: An updated analysis of public attitudes and beliefs, 1996-2001. (Research Paper, NC-340). Forest Service, North Central Research Station.

Bowker, J. M., English, B. K., \& Donovan, J. A. (1996). Toward a value for guided rafting on southern rivers. Journal of Agricultural and Applied Economics, 28, 423-432.

Bockstael, N. E., \& McConnell, K. E. (1991). Public goods as characteristics of non-market commodities. Economic Journal, 103, 1244-1257.

Cameron, A. C., \& Trivedi, P. K. (1998). Regression analysis of count-data. NY: Cambridge University Press.

Champ, P. A., \& Bishop, R. C. (1996). Evidence on the accuracy of expenditures reported in recreational surveys. Journal of Agricultural and Resource Economics, 21, 150-159.

Chase, L. C., Lee, D. R., Schulze, W. D. Schulze, \& Anderson, D. J. (1998). Ecotourism demand and differential pricing of national park acess in Costa Rica. Land Economics, 74, 466-482.

Englin, J., \& Cameron, T. A. (1996). Augmenting travel cost models with contingent behavior data. Environmental and Resource Economics, 7, 133-147.

Grijalva, T. C., Berrens, R. P., Bohara, A. K., \& Shaw, W. D. (2002). Testing the validity of contingent behavior trip responses. American Journal of Agricultural Economics, 84, 401-414.

Hellerstein, D., Woo, D., McCollum, \& Donnelly, D. (1993). ZIPFIP: A zip and fips database. Washington D.C.: USDA, Economic Research Service, Resources and Technology Division, 1301 New York Ave. NW, Room 438. 
Hudson, D. (2003). Problem solving and hypothesis testing using economic experiments. Journal of Agricultural and Applied Economics, 35, 337-347.

Kakoyannis, C., \& Stankey, G. H. (2002). Assessing and evaluation recreation uses of water resources: Implications for an integrated management framework. (General Technical Report, PNW-GTR536). Forest Service, Pacific Northwest Research Station.

Kennedy, P. (1996). A guide to econometrics. ( $3^{\text {rd }}$ ed.). Cambridge, MA: The MIT Press.

King, G., Tomz, M., \& Wittenberg, J. (2000). Making the most of statistical analyses: improving interpretation and presentation. American Jourmal of Political Science, 44, 341-355.

Kerkvliet, J., \& Nowell, C. (1999). Heterogeneous visitors and the spatial limits of travel cost model. Journal of Leisure Research, 31, 404419.

Loomis, J. B. (1993). An investigation into the reliability of intended visitation behavior. Environmental and Resource Economics, 3, 183-191.

Mendelsohn, R., Matzkin, R., Peterson, G., \& Rosenthal, D. (1994). Using conditional utility models for measuring welfare (Research Note RM-527.) USDA Forest Service, Rocky Mountain Forest and Range Experiment Station, 1-4.

Moore, R. L., \& Driver, B. (2005). Introduction to outdoor recreation: Providing and managing natural resource based opportunities. Appendix A, Recreation Experience Preference Scales (pp. 315320). State College, PA: Venture Publishing, Inc.

Moore, R. L., \& Siderelis, C. (2003). Use and economic importance of the West Branch of the Farmington River. Final Report. Washington D.C.: American Rivers, Inc. and Park Planning and Special Studies and Rivers, Trails and Conservation Assistance Programs of the National Park Service.

Parsons, G. R. \& Wilson, A. J. (1997). Incidental and joint consumption in recreation demand. Agricultural and Resource Economics Review, 26, 107-115.

Siderelis, C., Moore, R., \& Lee, J. (2000). Incorporating users' perceptions of site quality in a recreation travel cost model. Journal of Leisure Research, 32, 406-414.

Smith, K. V. \& Kaoru, Y. (1986). Modeling recreation demand within a random utility framework. Economics Letters, 22, 395-399.

Stata Corporation (2003). Stata statistical software. Release 8.0. College Station, TX: Stata Corporation.

USDA Forest Service (2002). Chattooga Wild and Scenic River. Columbia, SC: Sumter National Forest. Available at: http://www.fs.fed.us/r8/fms/rec/Chattooga.pdf

Whitehead, J. C., Haab, T. C., \& Huang, J. (2000). Measuring recreation benefits of quality improvements with revealed and stated behavior data. Resource and Energy Economics, 22, 339354.

Woolridge, J. M. (2000). Introductory econometric: A modern approach. US: Thomson Learning, South-Western College Publishing. 
Copyright of Journal of Leisure Research is the property of National Recreation \& Park Association and its content may not be copied or emailed to multiple sites or posted to a listserv without the copyright holder's express written permission. However, users may print, download, or email articles for individual use. 